\title{
GEOGEBRA COMO OPÇÃO METODOLÓGICA
}

\author{
KARINA MARIA DA FONSECA LUCIANO*
}

\begin{abstract}
Resumo
O Geogebra é um Software de matemática que combina de maneira dinâmica a geometria e a álgebra. As possibilidades de ajuda que o Software Geogebra pode acrescentar ao processo de ensino e aprendizagem já foram comprovadas. Contudo, o papel do professor na criação de condições à sua inserção na sala de aula é fundamental. Dessa forma, este artigo traz uma análise da aplicação do Geogebra como recurso didático, a exemplo da aplicação no processo de ensino e aprendizagem de triângulos para o Ensino da Matemática. Trata-se de uma revisão bibliográfica em que conceitos e teorias de autores como Nóbriga (2012), Araújo (2011) e outros, foram analisadas. Diante de tais análises, algumas considerações foram tecidas, como por exemplo, sua significativa contribuição no entendimento das propriedades dos triângulos.
\end{abstract}

\section{Introdução}

A sociedade contemporânea tem em sua composição pessoas com conhecimentos de recursos tecnológicos, inclusive do uso do computador, e, em se tratando da educação não é diferente. Vive-se numa via de mão dupla: por um lado, boa parte dos alunos detém esse conhecimento, por outro, a maioria dos professores não tiveram essa oportunidade em sua formação inicial, tiveram apenas noções básicas e pouca, ou nenhuma, metodologia de aplicabilidade dessa ferramenta; outros, sequer conhecem Softwares com aplicações voltadas a educação.

Nesse contexto, cabe uma preocupação com o trabalho de aperfeiçoamento dos professores. Para Zulato (2002, p. 09) “essa preparação não se trata apenas de um treino técnico de conhecimento e operação de programas e equipamentos, mas sim, propostas metodológicas de aplicações na prática pedagógica”. O programa Geogebra foi

Palavras-chave: Opção Metodológica 1, Software educativo 2, Ensino de Matemática 3.

*Mestre em engenharia Gestão de Processos e Sistemas, Instituto de Educação Tecnológica (Ietec) Professora de Cálculo Diferencial e Integral na Faenge-Uemg, Professora de Cálculo Diferencial e Integral, Geometria Analítica e Álgebra Linear no Instituto Ensinar do Brasil. karina- luciano@ hotmail.com 
desenvolvido por Markus Hohenwarter, professor da Universidade de Salzburg, em 2001, com o intuito de dinamizar o estudo da Matemática podendo ser encontrado com facilidade em sites de busca. É um Software de matemática dinâmica, gratuito, disponível em várias plataformas, para todos os níveis de ensino.

Segundo Nóbriga et al (2012) "é atualmente um dos Softwares educativos de matemática mais utilizados no mundo". Além disso, várias pesquisas apontam contribuições de programas desse tipo para o ensino de Matemática.

\footnotetext{
Tais recursos podem favorecer a valorização da capacidade argumentativa nas atividades matemáticas, tornando-se, na medida em que a exploração matemática acontece, um terreno vasto para experimentação, observação, demonstração, elaboração e construção de conjecturas (SHEFFER; BRESSAN e CORRÊA, 2010, p.52 apud NÓBRIGA et al, 2012, p. 1).
}

Recursos como o Geogebra proporcionam aos alunos momentos de interação, e despertam maior interesse, uma vez que estes passam a agir como construtores de seu próprio conhecimento. Logo, se faz necessário propostas de integração desse Software no ensino de matemática.

Neste sentido, propõe-se a aplicação do Geogebra, como uma alternativa de recurso didatico no ensino de Matemática. As atividades propostas, além da aplicação do Software ao ensino de Matemática, possibilitam a utilização do laboratório de informática, uma vez que, segundo Borba e Penteado (2007, p. 33) “o uso de computadores e calculadoras no ensino representa um dos itens integrantes das novas Tendências Metodológicas da Educação Matemática", cujo objetivo é a melhoria do Ensino de Matemática.

Para alcançar a melhoria do ensino de matemática e mantê-lo em um nível de alta qualidade, a Educação Matemática desenvolve várias atividades em diferentes estados brasileiros por vários educadores matemáticos. Segundo Mendes (2009, p. 23) essas pesquisas têm como metas "desenvolver, testar e divulgar métodos inovadores de ensino; elaborar e implementar mudanças curriculares além de desenvolver e testar materiais de apoio para o ensino de matemática". Essas pesquisas contribuíram também para o surgimento de novas diretrizes metodológicas denominadas Tendências Metodológicas da Educação Matemática, que segundo Mendes (2009) são: 


\begin{abstract}
O uso de materiais concretos e jogos; a etnomatemática: uma abordagem sociocultural e cognitiva; a modelagem matemática e a representação do pensamento matemático; a história da matemática e o ensino da matemática escolar; o uso de computadores e calculadoras no ensino da matemática; e, os estudos em Didática da Matemática.
\end{abstract}

Para o desenvolvimento e análise dessa proposta, esta pesquisa baseia-se no método de revisão bibliográfica, que segundo Gil (2002, p. 44) “é desenvolvida com base em material já elaborado, constituído principalmente de livros e artigos científicos”. Assim, esta pesquisa foi composta pelas seguintes etapas: escolha do tema; levantamento bibliográfico; busca de fontes; leitura do material; fichamento; organização lógica do assunto e redação do texto.

Com a finalidade de facilitar o entendimento, iniciou-se a pesquisa com uma apresentação básica sobre o que é o Geogebra, seguido de uma breve explanação do que são polígonos, com ênfase nas propriedades inerentes aos triângulos. Na sequência realizam-se as demonstrações destas propriedades com auxílio do Software Geogebra.

\title{
2 O uso do software Geogebra: desafios e possibilidades
}

Com referência ao Ensino de Matemática, encontra-se nas recomendações contidas nos Parâmetros Curriculares Nacionais do Ensino Médio (PCNEM) parte III - Ciências da Natureza, Matemática e suas Tecnologias, uma alusão concreta sobre a importância natural das calculadoras e computadores, que permitem a abordagem de problemas com dados reais, requerendo habilidades de seleção e análise de informações por parte do docente. Conforme os PCN:

\footnotetext{
Embora os computadores ainda não estejam amplamente disponíveis para a maioria das escolas, eles já começam a integrar muitas experiências educacionais, prevendo-se sua utilização em maior escala em curto prazo. Isso traz como necessidade a incorporação de estudos nessa área, tanto na formação inicial como na formação continuada do professor do ensino fundamental, seja para poder usar amplamente suas possibilidades ou para conhecer e analisar softwares educacionais (BRASIL, 2001, p. 47).
}

Esses estudos trarão condições à integração dos computadores no processo de ensino e aprendizagem de forma efetiva e eficaz. Segundo Borba e Penteado (2007, p.44) "as atividades com calculadoras gráficas e computadores, além de proporcionarem uma multiplicidade de representações, enfatizam a experimentação como um enfoque fundamental em ressonância com sua visão de conhecimento". Para estes, o enfoque 
experimental explora ao máximo as possibilidades de rápido feedback das mídias informáticas. A esse respeito, os autores dizem que:

O trabalho com a modelagem e com o enfoque experimental sugere que há pedagogias que se harmonizam com as mídias informáticas de modo a aproveitar as vantagens de suas potencialidades. Essas vantagens podem ser vistas como sendo a possibilidade de experimentar, de visualizar e de coordenar de forma dinâmica as representações algébricas, tabulares, gráficas e movimentos do próprio corpo (BORBA; PENTEADO, 2007, p.44).

Nesse contexto, faz-se necessário criar condições para tirar, ao máximo, proveito dessas vantagens e potencialidades. Entende-se, hipoteticamente, que a condição para melhor utilização dessa tecnologia como recurso didático no processo de ensino e aprendizagem está relacionada com a formação dos professores, seja inicial ou continuada. Nesse sentido Lorenzato (2010, p. 161) afirma que:

\footnotetext{
Resulta daí a importância de se implantar nas universidades que trabalham com formação inicial e continuada de professores e laboratórios de ensino mediados pelas TIC. Esse espaço - mais do que físico, um espaço de formação, apoiado por uma abordagem teórico-metodológica e conduzido pela mediação do professor - constituise em verdadeiro cenário interativo de aprendizagem colaborativa e conhecimento compartilhado (LORENZATO, 2010, p. 161).
}

Ações dessa natureza proporcionarão aos docentes conhecimentos e habilidades necessárias para a integração dessa tecnologia à sua prática cotidiana. Em se tratando de professores que possuem certo conhecimento dos softwares educacionais (conhecimento adquirido em sua formação inicial ou continuada), é importante que os mesmos, desenvolvam iniciativas para separá-los e utilizá-los de acordo com seu propósito enquanto educador. Assim, os PCN destacam que:

Quanto aos softwares educacionais é fundamental que o professor aprenda a escolhêlos em função dos objetivos que pretende atingir e de sua própria concepção de conhecimento e de aprendizagem, distinguindo os que se prestam mais a um trabalho dirigido para testar conhecimentos dos que procuram levar o aluno a interagir com o programa de forma a construir conhecimento (BRASIL, 2001, p. 47). 
A partir de então, os docentes poderão fazer um melhor uso e tirar um maior proveito dessa ferramenta como instrumento metodológico, possibilitando assim, um uso efetivo dos laboratórios de informática no processo de ensino e aprendizagem.

\section{Uma pequena introdução ao Geogebra}

O Geogebra é apresentado em uma planilha contendo uma Janela de Álgebra (à direita) e uma Área de Trabalho (à esquerda) entre a Barra de Ferramentas e o Campo de Entrada. Cada elemento da Área de Trabalho é descrito algebricamente na janela da Álgebra ao lado, conforme mostra a Figura 1. As entradas dos objetos com as propriedades desejadas podem ser na forma de comandos no Campo de Entrada ou através da Barra de Ferramentas na Área de Trabalho.

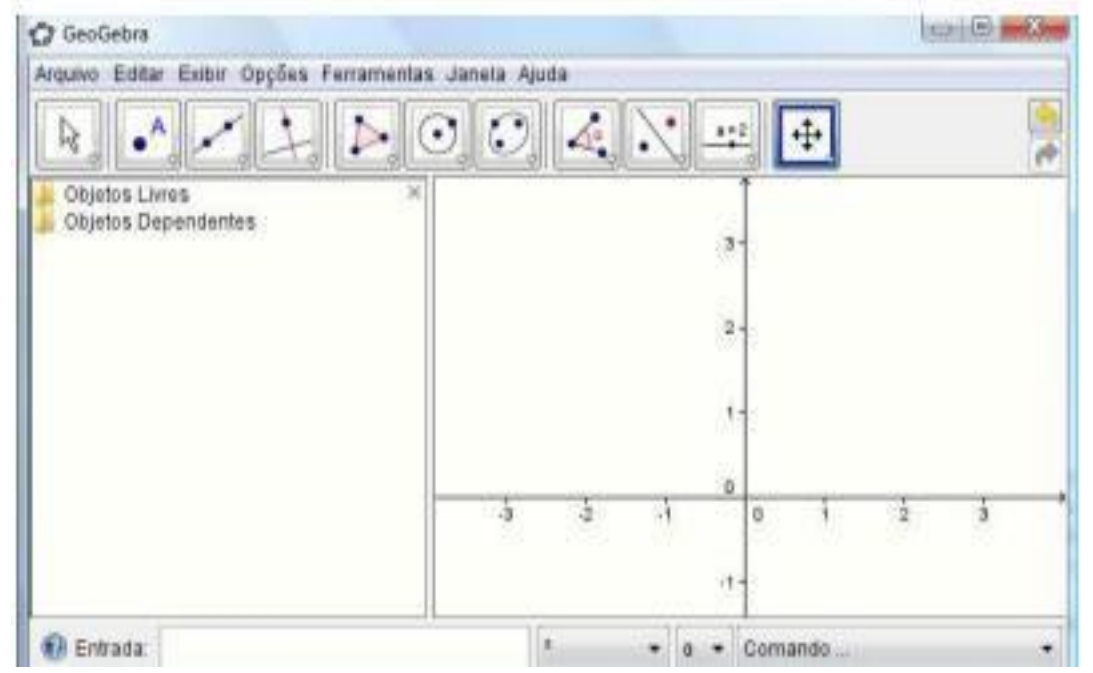

Figura 1-Tela inicial do programa Geogebra

A primeira barra de ferramentas contém onze (11) ícones (ferramentas indispensáveis às construções) expostos em um quadradinho com uma figura que o representa. Cada um desses ícones é composto de outros sub-ícones incluídos com a função inicial descrita, conforme mostra a Figura 2.

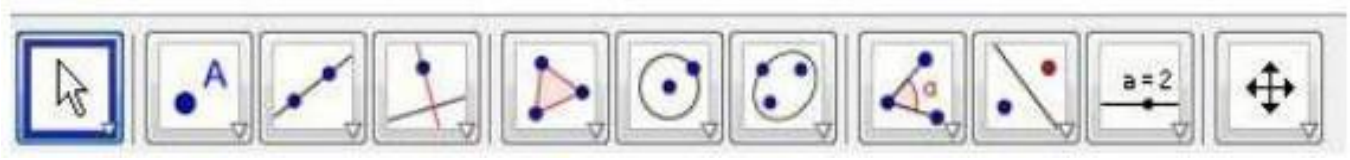

Figura 2- Barra de ferramentas do Programa Geogebra 
Para fazer uso de qualquer uma das ferramentas, basta clicar na seta do canto inferior direito de cada caixa de ferramenta/ícone correspondente, escorregar o botão do mouse para baixo e escolher o ícone/ferramenta que melhor lhe convém.

\section{Polígonos}

Entre os polígonos, os triângulos são considerados um dos polígonos mais estudados e que apresentam grande dificuldade para os alunos. Esta seção se destina a fazer uma demonstração do uso do programa Geogebra como facilitador do ensino, apresentando os elementos, ângulos e propriedades do triangulo e o uso do Geogebra como opção metodológica no processo de ensino e aprendizagem de Matemática.

Ao se analisar, em um plano, uma linha L composta por segmentos de reta, tais que: Cada ponto de qualquer um deles é ponto de dois e apenas dois deles; Dois segmentos consecutivos quaisquer, entre eles, não são colineares;

Dois segmentos não consecutivos quaisquer, entre eles não tem pontos em comum.

A linha L separa o plano em duas regiões, das quais uma é restringida. A união da linha L com essa região limitada é chamada de polígono (PAIVA, 2009, p. 60), conforme a Figura 3.

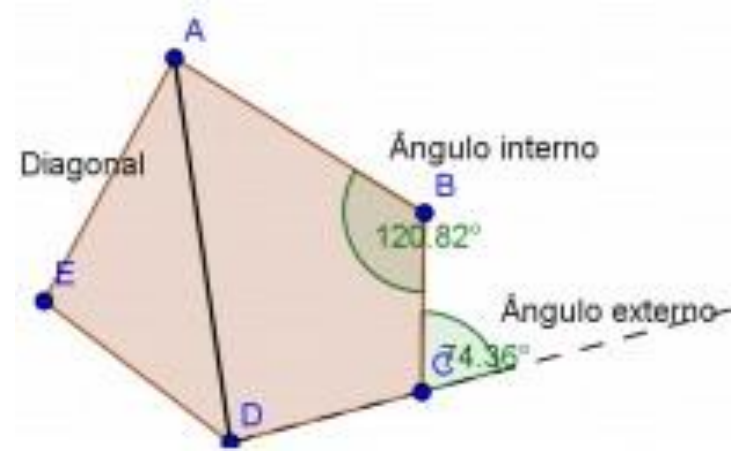

Figura 3 - Polígono

Polígonos podem ser nomeados de acordo com seu número de lados, logo um polígono que tem três, quatro, cinco, ou seis lados, é chamado respectivamente de triângulo, quadrilátero, pentágono, hexágono, e assim continuamente; para os polígonos com mais de vinte lados é comum serem mencionados em função de seu número de lados, não lhes sendo produzindo nomes especiais. 


\subsection{Polígonos convexos}

Um polígono é chamado de convexo se a reta r que contém qualquer um de seus lados admite os demais lados contidos em um mesmo semiplano de origem r, caso contrário, falamos que o polígono é não convexo (PAIVA, 2009) conforme a Figura 4.

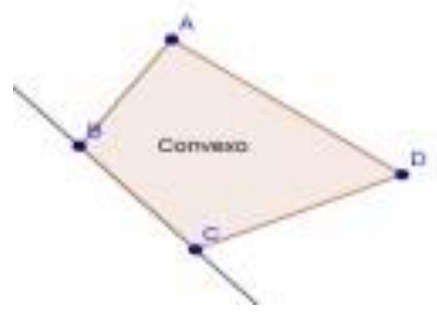

a)

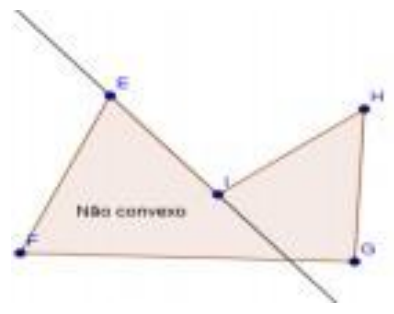

b)

Figura 4 - (a) polígono convexo, (b) polígono não convexo.

Entre os polígonos convexos, apresentamos os que têm todos os lados iguais entre si e todos os ângulos internos iguais entre si, estes são nomeados de Polígono regular. O triângulo, segundo Paiva (2009) é um polígono fundamental, tendo em vista que qualquer outro polígono consegue ser analisado como uma composição de triângulos arrumados lado a lado, daí a seriedade de se fazer um estudo mais delineado.

Os triângulos são dispostos quanto aos ângulos (acutângulo, obtusângulo e retângulo) e quanto aos lados (isósceles, escaleno e equilátero). A altura, bissetriz interna, mediana e mediatriz, além de ângulos internos cuja soma é igual a $180^{\circ}$, são consideradas na composição dos triângulos.

Como exemplo de aproveitamento do Geogebra no Ensino de Matemática, as demonstrações das propriedades relativas aos triângulos são descritas a seguir, cuja solução se produz com a utilização deste Software, que é o objetivo fundamental do estudo, como mencionado anteriormente. No programa Geogebra as caixas de ferramentas, da barra inicial foram enumeradas, de 01 a 11 (da esquerda para a direita), com a finalidade de promover a compreensão.

\subsection{Propriedades dos triângulos}

Os Triângulos isósceles, que consistem em dois lados iguais entre si é possível encontrar as seguintes propriedades: o triângulo tem dois lados com medidas congruentes, logo os ângulos opostos a esses lados possuem medidas congruentes; o triângulo que tem 
dois ângulos com medidas congruentes, logo os lados opostos a esses ângulos possuem medidas congruentes; a altura, a mediana e a bissetriz referentes à base do triângulo isósceles possuem segmentos coincidentes e permanecem contidas na mediatriz relativa a essa base (PAIVA, 2009).

Estas propriedades, estudadas no Geogebra podem ser analisadas através de demonstrações que seguem os seguintes passos: clicar no segundo ícone da barra de ferramentas, selecionar novo ponto, localizar os pontos A e B; no quarto ícone, escolher a mediatriz, definir mediatriz entre $\mathrm{A}$ e $\mathrm{B}$, respectiva à base do triângulo; no segundo ícone, selecionar novo ponto (ponto C) sobre a mediatriz, definindo os vértices do triângulo; no quinto ícone, selecionar o polígono, definir o triângulo e juntar os pontos A, B e C; no oitavo ícone, escolher a distância clicando sobre os vértices A e C, definir a medida do lado AC, de maneira igual e definir a medida dos diferentes lados do triângulo, compreendendo-se a congruência entre os lados; no oitavo ícone, na alternativa ângulo, clicar sobre os vértices $\mathrm{B}, \mathrm{A}, \mathrm{C}$, nesta ordem definindo a medida do ângulo $\mathrm{A}$, e em seguida clicar sobre os vértices $\mathrm{C}, \mathrm{B}, \mathrm{A}$, nesta ordem, definindo a medida do ângulo $\mathrm{B}$, compreendendo a congruência entre os ângulos.

Nesse momento o aluno percebe a validação das propriedades enunciadas. A partir daí, no campo visual verifica-se que a mediana, a bissetriz e a altura relativa à base do triângulo isósceles são segmentos coincidentes e estão contidas na mediatriz relativa a essa base, conforme mostra a Figura 5.

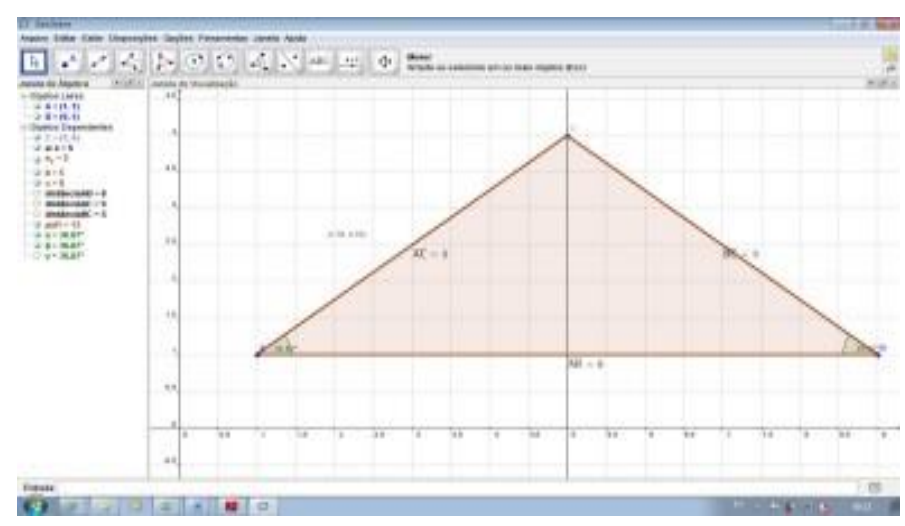

Figura 5 - Tela de demonstração do Geogebra trabalhando com um triângulo.

Fazendo uso do Geogebra, para verificar a veracidade das propriedades, além do enunciado da propriedade, o aluno pode, ao realizar a construção de um triângulo isósceles, visualizar os valores dos lados do triângulo, bem como os valores dos ângulos. 
Gravina (1996) apud Reis (2010) afirma que esse aplicativo pode ser trabalhado de duas formas: "na primeira, os próprios alunos constroem as figuras, tendo como objetivo o domínio dos procedimentos para a construção das mesmas; na segunda, o professor disponibiliza algumas figuras prontas aos alunos para que estes possam reproduzi-las”. O objetivo desta última modalidade de trabalho é possibilitar que, por meio da experimentação, os alunos descubram as invariantes das propriedades das figuras reproduzidas.

Em se tratando de um triângulo equilátero, o que possui os três lados congruentes entre si, Paiva (2009), afirma que "cada ângulo interno de um triângulo equilátero mede $60^{\circ}$ ", propriedade verificada facilmente ao se construir um triângulo equilátero, com o auxílio do Geogebra. Para se determinar as medidas de seus ângulos é preciso clicar no quinto ícone da barra de ferramentas (opção polígono regular) visto que se trata de um triângulo equilátero, e em seguida clicar duas vezes na área geométrica, em pontos distintos. Aparecerá uma caixa de diálogo "aplicar 3", clica-se em aplicar e estará construído o triângulo equilátero; no oitavo ícone, opção ângulo, determina-se a medida dos ângulos do triângulo, verificando-se, no campo visual a veracidade da propriedade, conforme a Figura 6.

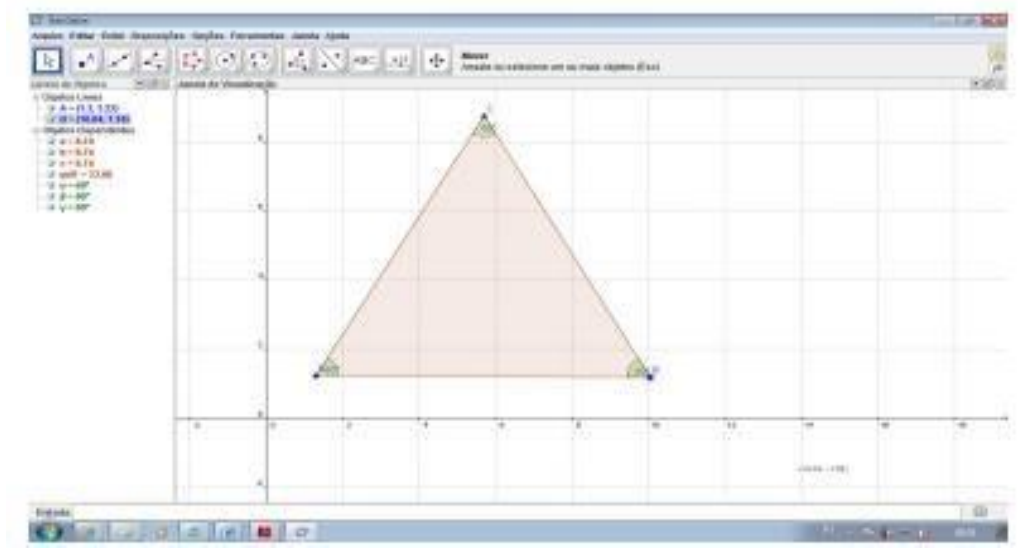

Figura 6 - Tela do Geogebra com a demonstração.

Já no caso de um triângulo retângulo que possui um ângulo interno reto, os lados do triângulo que formam esse ângulo reto são chamados de catetos, e o terceiro lado é chamado de hipotenusa. Paiva (2009), destaca duas propriedades:

Os ângulos agudos de um triângulo retângulo são complementares, logo: 


$$
\propto+\beta=90^{\circ}
$$

Em todo triângulo retângulo, a mediana relativa à hipotenusa (BM) mede metade da hipotenusa (AC), logo:

$$
B M=\frac{A C}{2}
$$

Para justificar tais propriedades, com auxílio do Geogebra, basta construir um retângulo $\mathrm{ABCD}$, e ao determinar suas diagonais, sabendo que estas são congruentes e que o ponto em comum entre as mesmas é o ponto médio de cada uma. O Programa Geogebra verifica a validade desta propriedade seguindo os seguintes passos: clica-se no segundo ícone da barra de ferramentas, opção novo ponto, localiza-se os pontos $\mathrm{A}(1,1)$, B $(1,4), C(5,4)$ e D $(5,1)$; no quinto ícone, opção polígono, determina-se o retângulo $\mathrm{ABCD}$, unindo os pontos; no terceiro ícone, opção segmento definido por dois pontos, determina-se as diagonais $\mathrm{BD}$, clicando sobre os pontos $\mathrm{B}$ e $\mathrm{D}$, e $\mathrm{AC}$ de modo análogo; no segundo ícone, opção intersecção entre objetos, determina-se a intersecção (M) entre as diagonais do retângulo. Nesse instante pode-se mostrar o que enfatiza a segunda propriedade, para tal, seleciona-se oitavo ícone, opção distância, clica-se sobre os vértices $\mathrm{A}$ e $\mathrm{C}$, determinando a medida da diagonal $\mathrm{AC}$ que equivale à hipotenusa do triângulo $\mathrm{ACD}$, de modo análogo determina-se a medida do segmento BM, demonstrando que a mediana relativa à hipotenusa $(\mathrm{BM})$ mede metade da hipotenusa $(\mathrm{AC})$, conforme a segunda propriedade; concluindo a demonstração.

Para demonstrar que os ângulos agudos são complementares, clica-se no quinto ícone, opção polígono, e em seguida clica-se sobre os vértices A, B, D, nesta ordem destacando o triângulo $\mathrm{ABD}$; assim mostra que os ângulos agudos de um triângulo são complementares, conforme a descreve a primeira propriedade, para isto, no oitavo ícone, opção ângulo, clica-se nos vértices A, B, D, nesta ordem determinando o ângulo agudo B, em seguida clica-se sobre os vértices $\mathrm{B}, \mathrm{D}, \mathrm{A}$, nesta ordem, determinando o ângulo agudo D; concluindo a demonstração. Ao realizar esta última operação verifica- se a complementariedade entre os ângulos agudos, bastando, apenas, somar os valores dos ângulos fornecidos pelo Geogebra. A Figura 7 representa esta demonstração. 


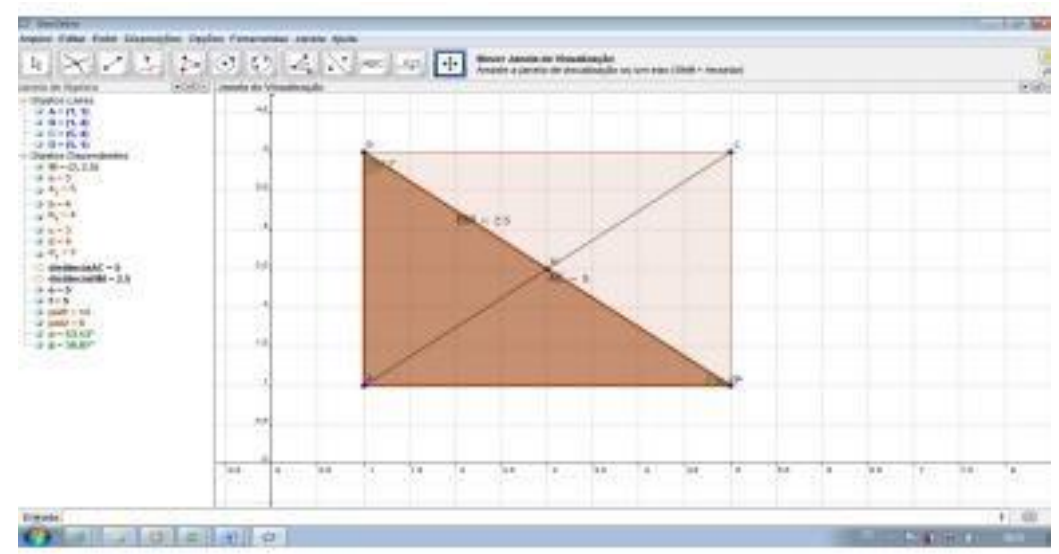

Figura 7 - Dois ângulos são complementares quando a soma de suas medidas é $90^{\circ}$.

A figura acima demonstra também que os valores dos segmentos $\mathrm{BM}=2,5$ e $\mathrm{AC}=5$, o que comprova que a mediana relativa à hipotenusa equivale à metade da medida da hipotenusa, bem como os valores relativos aos ângulos agudos, possibilitando, assim a visualização da complementariedade entre os mesmos.

O Geogebra, na demonstração dessas propriedades, proporciona ao aluno, em seu campo visual, exatamente, o que enfatizam as mesmas. Desta forma, segundo Araújo (2011) "as figuras tornam-se agentes no processo investigativo", já que o aluno pode perceber a diferença entre desenhar e construir uma figura, verificando que, para construíla não basta apenas chegar a uma aproximação desejada, mas ter a clareza sobre as propriedades e os diferentes elementos que ela possui de forma que ao ser arrastada mantenha as características primitivas.

\section{Considerações Finais}

Existe em leque vasto de tópicos que podem ser abordados, explorados com os recursos do Software Geogebra. Esta pesquisa possibilitou concluir que o Geogebra se constitui uma boa alternativa metodológica para professores que buscam dinamizar as aulas de matemática, sendo, este, mais uma ferramenta disponível para a melhora do processo de ensino e aprendizagem, desde que o professor tenha o domínio do conteúdo e que os aspectos operacionais do Software sejam problemas cujas resoluções aconteceram durante o processo.

Além de o Geogebra ser uma sugestão a ser integrada a prática dos docentes de Matemática, o programa também se apresenta como uma opção para utilização mais 
efetiva dos laboratórios de informática como recurso didático, justificando assim, o porquê deste Software representar uma das Tendências Metodológicas para o Ensino de Matemática.

O uso do computador tem sido fortemente recomendado no ensino de Matemática. A utilização do computador com aplicação de Softwares de geometria, como é o caso do Geogebra, permite a exploração de figuras geométrica, possibilitando que o aluno construa suas próprias hipóteses e que possa verificar se elas são válidas, além de averiguar a validade das propriedades já enunciadas, ou propostas nos livros didáticos.

O arrastar é uma das principais características dos Softwares de Geometria Dinâmica, visto que ao arrastar uma figura o aluno, poderá observar todos os casos possíveis da figura, para um mesmo conjunto de figuras com a mesma propriedade, proporcionando assim, baseado na exploração, novas possibilidades para o ensino e aprendizagem de Matemática.

\section{Referências}

ARAÚJO, W. A.; GOMES, A. M. F. O geogebra como recurso didático no ensino da geometria analítica. V Coloquio Internacional "Educação e Contemporaniedade". São Cristovão - Se: ISSN: 1982-3657, 2011.

BORBA, M. C.; PENTEADO, M. G. Informática e Educação Matemática. 3. ed: Autêntica, v. Tendências em Educação Matemática: Belo Horizonte, 2007.

BRASIL / MEC / SECRETARIA DE EDUCAÇÃO FUNDAMENTAL. Parâmetros Curriculares Nacionais: matemática. 3. ed. Brasília: MEC/SEF, v. 3, 2001.

GIL, A. C. Como elaborar projetos de pesquisa. $4^{\text {a }}$. Ed. Atlas: São Paulo, 2002.

LORENZATO, S. O Laboratório de ensino de matemática na formação de professores. Campinas, 2010.

Manual do Geogebra. Disponível em: <https://wiki.geogebra.org/pt/Manual>. Acesso em 11 jun. 2018.

NÓBRIGA, J. C. C.; SANTOS, G. L.; ARAÚJO, L. C. L.; FEREIRA, B. S.; LIMA, R. GGBOOK: uma interface que integrará os ambientes de texto e gráficos no Geogebra. Revista do Instituto Geogebra Internacional de São Paulo.v. 01, n. 01, p. 03 - 12. ISSN 2237 - 9657. São Paulo, 2012.

PAIVA, M. Matemática-1 Ed.- São Paulo: Moderna, 2009. 
REIS, H. G. P; LINS, A. F. O uso do Geogebra no auxílio à aprendizagem dos conceitos de grandezas e medidas geométricas. VI Encontro Paraibano de Educação Matemática. Monteiro - PB: ISSN 2179 - 2593. 2010.

ZULATTO, R. B. A. Professores de Matemática que Utilizam Softwares de Geometria Dinâmica: suas características e perspectivas. Dissertação. Universidade Estadual Paulista - UNESP, 2002. 